\title{
Mortality, Human Capital and Persistent Inequality
}

\author{
Shankha Chakraborty* \\ University of Oregon
}

\author{
Mausumi Das ${ }^{\dagger}$ \\ Delhi School of Economics
}

\begin{abstract}
Available evidence suggests high intergenerational correlation of economic status, and persistent disparities in health status between the rich and the poor. This paper proposes a novel mechanism linking the two. We introduce health human capital into a two-period overlapping generations model. Private health investment improves the probability of surviving from the first period of life to the next and, along with education, enhances an individual's labor productivity. Poorer parents are of poor health, unable to invest much in reducing mortality risk and improving their human capital. Consequently, they leave less for their progeny. Despite convex preferences, technology and complete markets, initial differences in economic and health status may perpetuate across generations.
\end{abstract}

Keywords: Life Expectancy, Health, Human Capital, Income Distribution JEL Classification: I12, I20, O15

*Department of Economics, University of Oregon, Eugene, OR 97403-1285, USA. Email: shankhac@oregon . uoregon.edu

${ }^{\dagger}$ Department of Economics, Delhi School of Economics, University of Delhi, Delhi 110007, India. Email: msmd@hotmail.com 


\section{Introduction}

This paper studies the interaction between wealth distribution and health status in a dynamic model of human capital investment. We show that, even when technologies and preferences are convex and markets complete, wealth and health inequality may persist across generations interlinked by wealth transmission through inheritance.

Intergenerational transmission of inequality and its persistence have received considerable attention in development economics in recent years. The issue is of interest not only because of its implications for intergenerational mobility and equity, but also from the point of view of efficiency in so far as inequality hinders an economy's growth process. Recent studies estimating intergenerational earning correlation for the US economy find significant degree of persistence, with the persistence coefficient lying between $0.4-0.6$ (Solon, 1992, Zimmerman, 1992, Mulligan, 1997). Examining British data Dearden et al. (1997) also report intergenerational earnings correlation in the range of $0.5-0.6{ }^{1}$ Empirical evidence thus suggests substantial inertia in economic and social mobility in the developed industrialized world, a result that is unlikely to be different for developing countries (Solon, 2002).

The current theoretical literature on persistent inequality focuses almost exclusively on a specific channel that operates through credit market imperfections. ${ }^{2}$ This paper, in contrast, explores an alternative mechanism of the transmission of poverty, one which operates through endogenous mortality risks. We postulate a positive relationship between the probability of survival and private health investment and show that the resulting interplay between income and mortality can be instrumental in generating poverty traps by altering the incentives that poorer households face.

The correlation between adult health and socioeconomic status is well-documented. For example, the age-adjusted relative risk of death in the US is about two to three times higher for people at the bottom of the income distribution compared to those at the top (Sorlie et al., 1995). Mortality rates in the poorer areas of Porto Alegre, Brazil, are about 75\% higher than in the richer areas (World Bank, 1993). Women from the poorest quintile of Bangladesh's population are twice as likely to have low body mass index (BMI) compared to women from the richest quintile (World Bank, 2003).

\footnotetext{
${ }^{1}$ Piketty (2000) provides an excellent survey of the empirical literature on earnings persistence. Also see Stokey (1996).

${ }^{2}$ See Banerjee and Newman (1993), Galor and Zeira (1993), Freeman (1996), Aghion and Bolton (1997), Picketty (1997), Maoz and Moav (1999) and Ghatak and Jiang (2002) for example. A different strand of this literature highlights the role of externalities associated with human capital formation in explaining persistent poverty. Examples include Benabou (1996), Daurlaf (1996), Galor and Tsiddon (1997).
} 
In examining the determinants of mortality among whites and non-whites in the US, Menchik (1993) finds that the mortality difference between different ethnic groups reduces dramatically when variables related to economic status are controlled for. Wilkinson (1996) reports that blue-collar workers are more likely to die from 80 percent of the 80 most common causes of death than white-collar workers. More recently, Lantz et al. (1998) find income to have strong and significant effects on mortality even after controlling for age, race, urbanization, sex, education and life style factors. ${ }^{3}$

We argue here that not only does poverty shorten the lifespan of a single generation, but when successive generations are linked through economic variables, mortality risk for the current generation has far reaching impact on income and mortality faced by its progeny.

Our argument is presented in terms of a two-period overlapping generations model with 'warm glow' bequest motives. The probability of survival from the first period of life to the next depends on privately incurred health expenditure. We show that a parent's low income status transmits to her descendents through two distinct channels. First, endogenous mortality implies that poorer people have lower probability of survival, and therefore they discount the future more heavily. Since bequests are typically left at the end of one's lifetime, a greater discount rate for poorer households implies that not only do they leave less bequests, they are also likely to leave a lower proportion of their earnings to their offsprings. This generates a convex bequest function, giving rise to threshold effects and poverty traps. ${ }^{4}$

Secondly, in the presence of endogenous mortality risks, income shocks become correlated with income, increasing the intergenerational persistence of poverty and mortality. When parents die prematurely, their children inherit their accumulated first period wealth as accidental bequests. When parents live for their entire two periods of life, they leave a part of their lifetime earnings as intended bequests. Since accidental bequests are typically lower than intended ones, a parent's premature death constitutes an income shock for the children. Premature death of the parent is, of course, a chance event, but its probability is endogenously determined. Since the poor face a higher probability of premature death, over time the household distribution of income will exhibit a greater concentration of mass on the tails - children from poorer households are more likely to stay poor (since they mostly receive accidental bequests), and vice versa for children from richer households. Thus endogenous

\footnotetext{
${ }^{3}$ Deaton (2003) provides an overview of this research.

${ }^{4}$ That a convex bequest function can generate poverty traps has been shown by Moav (2002). Instead of simply assuming a convex bequest function, as Moav does, we analyze conditions under which it obtains endogenously. For empirical support of convexity of bequest functions, see Menchik and David (1983).
} 
mortality alone can generate sufficiently strong persistence in our framework. ${ }^{5}$

The paper underscores the crucial role of health capital in explaining earning differentials and inequality across households over generations. The benchmark model, as described above, focuses on the impact of health on longevity. But apart from enhancing longevity, investment in health capital has other positive effects, notably on labour productivity. The link between productivity and health is multidimensional. Investment in health could directly enhance productivity and work capacity by increasing nutrient intakes. Furthermore, better nutrition and improved health during the early period's of one's life enhances cognitive abilities, thereby having an indirect effect on productivity. ${ }^{6}$ Keeping this in mind, we augment our benchmark model to allow for a positive link between health and productivity. We show that the persistence result gets strengthened in the presence of such human capital effects of health.

The paper contributes to the emerging literature on the persistence of poverty by providing an alternative explanation in terms of endogenous mortality. Related to our work, Ray and Streufert (1993) also consider a model of persistent inequality where the probability of survival is endogenous. But their persistence result stems entirely from the assumed non-convexity in labour supply capacity, ${ }^{7}$ whereas we highlight the crucial role played by endogenous mortality.

The paper proceeds as follows. In the next section, we describe the benchmark model and analyze wealth dynamics. In section 3, we extend the analysis to incorporate productivity enhancing effects of health and educational investment. Section 4 discusses the extent to which our results generalize in the presence of capital accumulation and externalities in health investment. We finally conclude in section 5 .

\section{Structure of the Model}

Consider a small, open, overlapping-generations economy that operates in a perfectly competitive world and faces a given world rate of interest. Time is discrete and infinite with $t=0,1,2, \ldots \infty$.

\footnotetext{
${ }^{5}$ Note that the two channels of persistence described here are quite independent. The latter mechanism would work even when bequest functions are concave.

${ }^{6}$ Behrman $(1993,1996)$ explore in detail such health-productivity linkages. Also see Strauss and Thomas (1997, 2000).

${ }^{7}$ The Ray-Streufert result does not change if one replaces the assumption of endogenous survival by exogenous survival.
} 


\subsection{Production}

Every period the economy produces a single good that may be consumed or invested. The output is produced using physical capital $(K)$ and efficiency units of labor $(H)$. The technology for this, $F(K, H)$, is Neoclassical and satisfies the usual Inada conditions.

In competitive product and factor markets, the economy-wide wage and interest rates are:

$$
\begin{aligned}
& w_{t}=f\left(\frac{K_{t}}{H_{t}}\right)-\left(\frac{K_{t}}{H_{t}}\right) f^{\prime}\left(\frac{K_{t}}{H_{t}}\right) \\
& r_{t}=f^{\prime}\left(\frac{K_{t}}{H_{t}}\right)-\delta
\end{aligned}
$$

where $f$ denotes the intensive-form technology and $\delta$ the depreciation rate on capital.

Given that this is a small open economy facing a constant interest rate, $r_{t}=\bar{r}$, the domestic capital to human capital ratio is pinned down at $\bar{k} \equiv f^{\prime-1}(\bar{r}+\delta)$, and this in turn fixes the domestic wage rate at $\bar{w}$. If $H_{t}$ changes over time due to human capital accumulation, capital $\left(K_{t}\right)$ flows in or out until physical capital per efficiency unit of labor returns to its previous level so that equilibrium wage and interest rates remain constant at $\bar{w}$ and $\bar{r}$ respectively. We denote the gross interest factor by $R \equiv 1+\bar{r}$.

\subsection{Preferences}

Let us normalize the size of new borns to unity. Individuals potentially live for two periods. For convenience, we will refer to these periods as "youth" and "old-age". Individuals live in youth for sure but they may or may not survive into old-age. The probability of surviving from youth to old-age is endogenous and depends upon an agent's health capital.

At the end of their youth, individuals give birth to a single offspring, before they realize their mortality shock. They are altruistic toward their children, deriving a "warm-glow" from bequests they leave to their offsprings at the end of their lives (Yaari, 1965, Andreoni, 1989, Galor and Zeira, 1993). We call such bequests intended, and distinguish them from unintended or accidental ones. Since agents consume in both periods of life, they save a positive amount. When they do not survive into old-age, their assets are passed on to their offspring as unintended bequests. Parents do not derive pleasure from such unintended transfers.

Individuals differ only with respect to their wealth levels $W_{t}^{i}$. The distribution of wealth in a particular generation $t$ is given by a cumulative distribution function $G_{t}(W)$ denoting 
the measure of individuals with wealth below $W$. The initial distribution $G_{0}$ is historically given.

Consider now the preferences of an individual born at $t$ with wealth $W_{t}$, inherited either as intended or unintended bequests. Expected lifetime utility of this individual is given by

$$
U_{t}=u\left(c_{t}^{t}\right)+\phi_{t}\left[u\left(c_{t+1}^{t}\right)+\theta v\left(b_{t+1}\right)\right]
$$

where $\phi_{t}$ denotes the probability of survival from youth to old-age. We are assuming here that utility from death equals zero and that $u$ and $v$ are concave and twice differentiable. An individual's chance of surviving beyond the first period depends upon her health capital $h_{t}$ according to

$$
\phi_{t}=\phi\left(h_{t}\right) \in[0,1]
$$

where the probability function satisfies

$$
\phi(0)=0, \quad \phi^{\prime}>0, \quad \phi^{\prime \prime} \leq 0, \quad \lim _{h \rightarrow 0} \phi^{\prime}(h)<\infty \quad \text { and } \quad \lim _{h \rightarrow \infty} \phi(h)=\bar{\phi} \leq 1 . \quad \text { (Assumption 1) }
$$

To economize on notation, we ignore any subjective discounting although this is easily incorporated.

An individual's health capital $h_{t}$ at the end of period $t$ is the outcome of her private health investment, amounting to $h_{t}$, undertaken in that period. Such health investments occur through net food intake (that is, nutrients available for cellular growth; see Fogel, 1993), personal care and hygiene, accessing clinical facilities and related medical expenditure that is key to mortality reduction. Since all individuals are born with identical amounts of health capital (normalized to one), any differences in health status within a particular cohort is entirely due to differences in health investment. ${ }^{8}$

Individuals work in both periods of life $(1,1)$, earning a wage rate $\bar{w}$. Out of this income, they consume, save and invest in health. Each individual gives birth to one offspring at the end of her youth. At the beginning of her old-age, an individual who invested $h_{t}$ in her health, realizes a mortality shock with probability $1-\phi\left(h_{t}\right)$. If she survives, she invests her youthful savings in capital, earning a gross return $R$ on it. But when she does not survive, her savings passes on to her offsprings. The offspring, however, cannot invest her parent's

\footnotetext{
${ }^{8}$ More generally $\phi^{i}=\phi\left(h^{i}, \kappa^{i}\right)$, where $\kappa^{i}$ is the innate health capital individual $i$ is born with. Here we have $\kappa^{i}=1$ for all $i$, and define $\phi\left(h^{i}\right) \equiv \phi\left(h^{i}, 1\right)$. This is obviously a simplifying assumption since offsprings do inherit part of their parent's health status naturally, through birth. Such intergenerational health transmissions would only increase the dimensionality of the dynamic system analyzed below, without adding much to our basic insights.
} 
savings on the market; in effect she receives an unintended bequest amounting to $s_{t}$, instead of $R s_{t} \cdot{ }^{9}$ Note that, unlike much of the literature on mortality risks (such as Yaari, 1965, Chakraborty, 1999, Kalemli-Ozcan et al., 2000), we do not assume the existence of perfect annuities markets here.

Surviving individuals allocate their second period labor and capital income between oldage consumption and bequests. Thus all generation- $t$ individuals face the following two budget constraints,

$$
\begin{aligned}
c_{t}^{t} & =\bar{w}+W_{t}-s_{t}-h_{t}, \\
c_{t+1}^{t} & =\bar{w}+R s_{t}-b_{t+1},
\end{aligned}
$$

the second one being relevant only when an individual survives into old age.

\subsection{Optimization}

A generation- $t$ individual's utility maximization problem is one of choosing the vector $\left(s_{t}\right.$, $\left.h_{t}, b_{t+1}\right)$ to maximize

$$
u\left(\bar{w}+W_{t}-s_{t}-h_{t}\right)+\phi\left(h_{t}\right)\left[u\left(\bar{w}+R s_{t}-b_{t+1}\right)+\theta v\left(b_{t+1}\right)\right] .
$$

An interior solution to this problem exists and is given by the following necessary and sufficient conditions:

$$
\begin{aligned}
u^{\prime}\left(c_{t}^{t}\right) & =R \phi\left(h_{t}\right) u^{\prime}\left(c_{t+1}^{t}\right), \\
u^{\prime}\left(c_{t}^{t}\right) & =\phi^{\prime}\left(h_{t}\right)\left[u\left(c_{t+1}^{t}\right)+\theta v\left(b_{t+1}\right)\right], \\
u^{\prime}\left(c_{t+1}^{t}\right) & =\theta v^{\prime}\left(b_{t+1}\right) .
\end{aligned}
$$

Together with the budget constraints (2) and (3), equations (4) - (6) implicitly define optimal savings, health investment and bequests as functions of an individual's level of wealth, $W_{t}$. Since bequests and savings determine intended and accidental bequests respectively, these optimal decisions will help us analyze the dynamics of wealth and health evolution in this economy.

\footnotetext{
${ }^{9}$ This assumption reflects the fact that obtaining access to parental wealth in case of accidental death of parent is a time-consuming and costly affair; it involves the legal costs of establishing one's claim to the property. For convenience we assume that such legal procedure does not involve any direct monetary cost, only the indirect cost of foregone interest income.
} 
For expositional purposes, it will be convenient to work with a CES utility function and assume that utility from bequests take the same functional form as utility from consumption. Accordingly, we assume that

$$
u(c)=\frac{c^{1-\sigma}}{1-\sigma}, \quad v(b)=\frac{b^{1-\sigma}}{1-\sigma}, \quad \sigma \in(0,1) .
$$

We restrict $\sigma$ to be less than 1 for two reasons. In the first place, we require the substitution effect of an interest rate change to dominate the income effect to generate a "well-behaved" savings function. Additionally, since utility from death is zero, having $\sigma>1$ would perversely yield lower utility from being alive and consuming a positive bundle of $\left(c_{t}^{t}, c_{t+1}^{t}, b_{t+1}\right)$.

The first-order conditions (4) - (6) corresponding to (7) are now given by

$$
\begin{aligned}
c_{t+1}^{t} & =\left[\phi\left(h_{t}\right) R\right]^{1 / \sigma} c_{t}^{t}, \\
(1-\sigma)\left(c_{t}^{t}\right)^{-\sigma} & =\phi^{\prime}\left(h_{t}\right)\left[\left(c_{t+1}^{t}\right)^{1-\sigma}+\theta\left(b_{t+1}\right)^{1-\sigma}\right], \\
b_{t+1} & =\beta c_{t+1}^{t},
\end{aligned}
$$

where $\beta \equiv \theta^{1 / \sigma}$.

To obtain optimal savings and bequest decisions, we proceed in several steps. First we substitute for $b_{t+1}$ in (9) using (10) to get

$$
(1-\sigma) R \phi\left(h_{t}\right)\left(c_{t+1}^{t}\right)^{-\sigma}=\phi^{\prime}\left(h_{t}\right)(1+\beta)\left(c_{t+1}^{t}\right)^{1-\sigma}
$$

which combined with (8) gives

$$
R(1-\sigma) \phi\left(h_{t}\right)=(1+\beta) \phi^{\prime}\left(h_{t}\right) c_{t+1}^{t}+A(1-\sigma)(1-\alpha)\left(\frac{\alpha A}{R}\right)^{\alpha /(1-\alpha)} \phi\left(h_{t}\right) .
$$

We can use this to express optimal second period consumption as a function of health investment,

$$
c_{t+1}^{t}=\left[\frac{(1-\sigma) R}{(1+\beta) \varepsilon_{\phi}}\right] h_{t},
$$

where $\varepsilon_{\phi} \equiv h \phi^{\prime} / \phi \in(0,1)$ is the elasticity of $\phi$ with respect to health capital. Note that $\sigma<1$ ensures that $c_{t+1}^{t} \geq 0$.

Now, using (10) and (11) in (3), we express optimal savings as

$$
s_{t}=\left[\frac{1-\sigma}{\varepsilon_{\phi}}\right] h_{t}-\frac{\bar{w}}{R} .
$$

Likewise, from (8) and (11), we have

$$
c_{t}^{t}=(R)^{-1 / \sigma}\left[\frac{(1-\sigma) R}{(1+\beta) \varepsilon_{\phi}}\right] h_{t}\left[\phi\left(h_{t}\right)\right]^{-1 / \sigma}
$$


Finally, we determine optimal health investment by substituting (12) and (13) into (2):

$$
h_{t}=W_{t}+\left[\frac{1+R}{R}\right] \bar{w}-\left[\frac{1-\sigma}{\varepsilon_{\phi}}\right] h_{t}-(R)^{-1 / \sigma}\left[\frac{(1-\sigma) R}{(1+\beta) \varepsilon_{\phi}}\right] h_{t}\left[\phi\left(h_{t}\right)\right]^{-1 / \sigma}
$$

or,

$$
\Gamma\left(h_{t}\right) \equiv \mu_{0} h_{t}+\mu_{1} h_{t}\left[\phi\left(h_{t}\right)\right]^{-1 / \sigma}=W_{t}+\left[\frac{1+R}{R}\right] \bar{w},
$$

where $\mu_{0} \equiv 1+(1-\sigma) / \varepsilon_{\phi}>0$ and $\mu_{1} \equiv(R)^{-1 / \sigma}\left[(1-\sigma) R /\left\{(1+\beta) \varepsilon_{\phi}\right\}\right]>0$. Equation (14) implicitly defines health investment as an increasing function of wealth (see below), which we denote by $h_{t}=\eta\left(W_{t}\right)$.

Equations (10), (11) and (12), imply that

$$
b_{t+1}=\left(\frac{\beta}{1+\beta}\right)\left(\frac{1-\sigma}{\varepsilon_{\phi}}\right) R \eta\left(W_{t}\right) \equiv \Psi_{1}\left(W_{t}\right)
$$

and

$$
s_{t}=\left(\frac{1-\sigma}{\varepsilon_{\phi}}\right) \eta\left(W_{t}\right)-\frac{\bar{w}}{R} \equiv \Psi_{2}\left(W_{t}\right),
$$

both of which are increasing in wealth. Longer-lived individuals are more patient decision makers since the probability of survival affects an individual's effective discount rate. Consequently, these individuals are more willing to save and leave larger bequests. Since health investment and wealth status are positively related, the implication is that offsprings of wealthier parents also enjoy prosperous and healthier lives.

\subsection{Optimal Health Investment}

Health being a normal good in this economy, individuals invest more in it the wealthier they are. But exactly how responsive health status is to economic status will matter for intergenerational wealth dynamics. Proposition 1 below states conditions for this.

Proposition 1 Optimal health investment, $h=\eta(W)$, implicitly defined by equation (14), satisfies the following properties:

(i) $\eta(0)>0$ as long as $\bar{w}>0$,

(ii) $\partial \eta(W) / \partial W \geq 0$ with $\lim _{W \rightarrow \infty} \partial \eta(W) / \partial W=0$, and

(iii) $\partial^{2} \eta(W) / \partial W^{2}<0$ for $\sigma<\varepsilon_{\phi(\eta(W))}, \partial^{2} \eta(W) / \partial W^{2}>0$ for $\sigma>\varepsilon_{\phi(\eta(W))}$, while $\lim _{W \rightarrow \infty} \partial^{2} \eta(W) / \partial W^{2}=0$. 
The technical part of this proposition is proved in Appendix A. To get an intuitive understanding, consider Figure 1 which depicts the relationship given by (14).

Figure 1(a) illustrates health investment for $\sigma>\varepsilon_{\phi}$. Here $\Gamma(0)=0$, with $\Gamma(h)$ monotonically increasing in health. $\Gamma(h)$ intersects $W+[(1+R) / R] \bar{w}$ only once and the optimal choice is given by $\eta(W)$. When $\sigma<\varepsilon_{\phi}$, as in Figure 1(b), $\Gamma(h)$ is U-shaped. $\Gamma(h)$ now intersects $W+[(1+R) / R] \bar{w}$ twice. It is straightforward to show that only the higher intersection point, labelled $\eta(W)$, satisfies the second order condition for utility maximization. ${ }^{10}$

Proposition 1 implies that $\eta(W)$ is concave or convex depending upon the relative magnitudes of $\sigma$ and $\varepsilon_{\phi}$. Of course, $\varepsilon_{\phi}$ need not be constant. In fact, when $\varepsilon_{\phi}$ is a decreasing function of $h$, as is intuitively plausible, $\eta(W)$ exhibits a convex-concave or concave-convexconcave pattern. To see this, consider two examples that satisfy Assumption 1. Suppose that $\phi$ is given by

$$
\phi(h)=\bar{\phi}\left[\frac{h}{1+h}\right]^{\tau}, \quad \tau \in(0,1) .
$$

The elasticity of this function, $\varepsilon_{\phi}=\tau /(1+h)$, monotonically falls with an individual's health status: one percent increase in health investment reduces mortality by less the healthier is the person. Two possibilities arise. If $\sigma>\tau$, we have $\sigma>\varepsilon_{\phi}$ for all $h$; this is the case illustrated by Figure 1(a). If instead, $\sigma<\tau$, optimal health investment is determined according to Figure 1(b). Define $h_{c}$ to be health investment such that $\varepsilon_{\phi\left(h_{c}\right)} \equiv \sigma$. Then for $h<h_{c}$, we have $\sigma<\varepsilon_{\phi}$, while $\sigma \geq \varepsilon_{\phi}$ otherwise. We also have $h_{c}>\underline{h}$ in this case.

An alternative $\phi$ is given by the weakly concave function,

$$
\phi(h)=\left\{\begin{array}{ll}
\bar{\phi}\left(h / h_{c}\right)^{\tau}, & \text { for } h<h_{c} \\
\bar{\phi}, & \text { for } h \geq h_{c}
\end{array}, \quad \tau \in(0,1) .\right.
$$

Its elasticity is $\tau$ for health below $h_{c}$, zero otherwise. Again $\tau$ may or may not be less than $\sigma$; but even if not, for $h>h_{c}$ we have $\sigma>\varepsilon_{\phi}$.

For both examples, if $\sigma>\tau, \eta(W)$ is initially convex, then concave. The concave part follows from the concavity of $\phi$ : increased wealth does not appreciably increase health investment at very high wealth levels. When $\sigma<\tau$, health investment is concave for $W \in$ $\left[0, \eta^{-1}\left(h_{c}\right)\right]$, then becomes convex, and finally concave.

A little intuition on this relationship between $\sigma$ and $\varepsilon_{\phi}$ will be helpful. There are essentially two ways individuals can increase their future utility here: by increasing their health capital $h_{t}$, which raises the weight attached to future utility, and by increasing $c_{t+1}^{t}$ and $b_{t+1}$

\footnotetext{
${ }^{10}$ For this case, we assume that $\bar{w}$ is greater than $R \underline{w} /(1+R)$, so that even individuals with no wealth invest a positive amount in health.
} 
directly through greater savings, $s_{t}$. Now consider the consumption Euler equation (4):

$$
u^{\prime}\left(c_{t}^{t}\right)=\phi\left(h_{t}\right) R u^{\prime}\left(c_{t+1}^{t}\right)
$$

and examine the effect of an increase in wealth. This obviously increases present consumption $c_{t}^{t}$, so that $u^{\prime}\left(c_{t}^{t}\right)$ falls. But since $h_{t}$ and $c_{t+1}^{t}$ are normal goods, an increase in wealth increases these too so that $\phi_{t}$ rises, while $u^{\prime}\left(c_{t+1}^{t}\right)$ falls. If $\sigma<\varepsilon_{\phi}, \phi(h)$ rises proportionately more than the fall in marginal utility. For the Euler equation to hold, $c_{t+1}^{t}$ has to rise proportionately more. Since $c_{t+1}^{t}$ can increase only through higher savings, this means savings has to rise proportionately more than health investment. Thus the proportionate rise in $h_{t}$ will be relatively less and we must have $\partial^{2} h_{t} / \partial W_{t}^{2}<0$. The bequest (and savings) function is concave in this case.

\subsection{Wealth Dynamics}

Given optimal bequest and savings decisions from (15) and (16) above, intergenerational wealth dynamics follows a nonlinear Markov process

$$
W_{t+1}^{i}=\Psi\left(W_{t}^{i}\right) \equiv \begin{cases}\Psi_{1}\left(W_{t}^{i}\right), & \text { with probability } \phi\left(h\left(W_{t}^{i}\right)\right), \\ \Psi_{2}\left(W_{t}^{i}\right), & \text { otherwise, }\end{cases}
$$

where $W_{0}^{i}$ is historically given by the initial distribution $G_{0}$.

We impose a restriction on the degree of altruism here. The term $\bar{w} / R$ that enters the optimal savings decision in equation (16) is the present value of second-period labor income, and would be zero if individuals were to work only in the first period of their lives. We assume that individuals are altruistic enough in the sense that,

$$
\theta>(1 / \bar{r})^{\sigma} .
$$

(Assumption 2)

This assumption ensures that even when individuals do not work in the second period, $\Psi_{1}(0)>\Psi_{2}(0)$. As long as Assumption 1 is satisfied, individuals at all wealth levels are economically better off with their parents surviving instead of dying prematurely. It also implies that the intended bequest line $\Psi^{1}$ is steeper than unintended bequests $\Psi^{2}$.

We now turn to an analysis of the wealth dynamics characterized by (19) above. As a by-product of this dynamics, we will learn the extent to which health status and mortality risks persist across generations. Observe first that endogenous mortality introduces a 'stickiness' to intergenerational economic status. Since they do not invest much in health, poorer individuals are more likely to die prematurely. Consequently they leave their offsprings lower 
assets than they otherwise would, and this generates a tendency for the progeny to remain mired in poverty and ill-health.

Contrast this to an environment where mortality is exogenously specified, independent of health and wealth. Such a stochastic model would have trouble accounting for observed correlations of intergenerational income and consumption. For example, using US data, Mulligan (1997) finds that estimates on these intergenerational correlations are in the range 0.7-0.8, much higher than we would expect from a model with exogenously driven stochastic shocks to income or wealth (see also Piketty, 2000). Our model of intergenerational wealth transmission effectively endogenizes these wealth and income shocks: the propensity to suffer from adverse wealth shocks is higher, the poorer are one's parents. Endogenous mortality risk, in other words, increases the correlation between parental and child economic and health status.

Exactly how persistent intergenerational wealth inequality is depends on whether or not (19) possesses a globally unique invariant distribution. This, in turn, is decided by the curvature of $\eta(W)$, which through equations (15) and (16), determines the shape of intended and accidental bequests. We illustrate three possibilities in Figures 2, 3 and 4.

In Figure 2 a unique and globally stable invariant distribution exists. Although $\eta\left(W_{t}\right)$ is initially convex, it occurs at relatively low wealth levels. ${ }^{11}$ Both $\Psi_{1}$ and $\Psi_{2}$ are concave in the relevant range, where they intersect the $45^{\circ}$ line. Figure 2 obtains when the expected bequest line $\Psi^{E}$ defined by

$$
\Psi^{E}\left(W_{t}^{i}\right) \equiv \phi\left(h\left(W_{t}^{i}\right)\right) \Psi_{1}\left(W_{t}^{i}\right)+\left[1-\phi\left(h\left(W_{t}^{i}\right)\right)\right] \Psi_{2}\left(W_{t}^{i}\right),
$$

has a slope less than unity at $\bar{W}$. The upper panel illustrates the dynamics of wealth: irrespective of initial wealth, all dynasties asymptotically converge toward $\bar{W}$. In the lower panel we show how the long-run wealth distribution $g_{\infty}$ evolves from an initial distribution $g_{0}$. This invariant distribution is unique, with a stable support $\left[\bar{W}_{2}, \bar{W}_{1}\right]$ and an expected wealth level of $\bar{W}$. The short-run dynamics imply that one would observe a significant degree of correlation in parents' and children's economic and health status, but such persistence would dissipate in the long-run.

Figure 3 illustrates the interesting possibility where even though $\Psi_{1}$ and $\Psi_{2}$ are concave in the relevant range, the expected bequest line $\Psi^{E}$ is not. ${ }^{12}$ The dynamics here are quite

\footnotetext{
${ }^{11}$ This is likely to arise when $\phi$ rises relatively fast with health investment.

${ }^{12}$ Recall that $\Psi_{1}$ is steeper than $\Psi_{2}$. Figure 3 is likely to arise the greater is the degree of altruism, $\theta$, relative to $(1 / \bar{r})^{\sigma}$. This follows from noting that $\partial^{2} \Psi^{E} / \partial W^{2}>0$ whenever $\partial \Psi_{1} / \partial W$ is "large enough" relative to $\partial \Psi_{2} / \partial W$.
} 
different. The long-run wealth distribution $g_{\infty}$ is non-ergodic, resulting in polarization of wealth and mortality compared to before. Dynasties starting with wealth levels below $\bar{W}$, exhibit a greater tendency to remain there. Expected long-run wealth, $\bar{W}$, thus acts like a poverty trap.

Extreme degrees of persistence and poverty trap result in Figure 4, where $\Psi^{1}, \Psi^{2}$ and thus, $\Psi^{E}$, are all non-concave in the appropriate range. The long-run outcome is evidently history-dependent. Families that start out with sufficient wealth, above $\bar{W}$, converge to a distribution on the support $\left[\bar{W}_{H}^{2}, \bar{W}_{H}^{1}\right]$. Those who do not, converge to $\left[\bar{W}_{L}^{2}, \bar{W}_{L}^{1}\right]$. The wealth level $\bar{W}$ once again acts as a threshold, determining exactly how persistent intergenerational health and wealth outcomes would be in the long-run.

Long-run persistence in wealth and health status obtains in our model due to the dependence of health and mortality on economic status. It may be argued in this context that medical innovations in the recent past has led to substantial mortality reduction across the world, and especially in developing countries, quite independent of income improvements. Indeed, in so far as medical innovations lead to exogenous reduction in adult mortality, it would undermine the importance of the persistence mechanism highlighted here. It is easy to see that exogenous improvements in the probability of survival would shift up the transition mappings in (19), allowing the poor to accumulate wealth, and reduce mortality, faster than before. Significant longevity improvements could even alter the wealth mapping from what Figure 4 depicts to something similar to Figure 2. However empirical evidence suggests that the impact of such medical innovations (essentially working through public health systems) has been far more visible in instances of sharp declines in infant and child mortality rates, rather than in adult mortality (World Bank, 1993). To the extent that exogenous medical innovations has had limited impact on adult mortality rates, the income-health link emphasized here plays a crucial role in generating persistence.

\section{Health, Education and Labor Productivity}

Our examination of the interdependence between health and economic outcomes in the previous section differs from existing analyses in one important respect. Much recent work on health human capital has focused on the implication of health for labor productivity, rather than for saving and investment decisions of the type we analyzed above.

Pioneering work by Robert Fogel has highlighted the historical importance of nutrition and living standard improvements for economic development. Fogel (1997), for instance, 
estimates that nutritional improvements alone contributed about $20-30 \%$ of the growth in British per capita income during 1780-1979 by bringing the impoverished into the labor force and by increasing the energy level available for work.

The evidence gleaned from a number of recent microeconometric studies on developing countries, reviewed by Strauss and Thomas (1998), shows health status and nutritional intake to be important for an individual's functionality and ability to work productively. Figure 5 , taken from there, illustrates this by plotting a positive relationship between (log) wages and body mass index (BMI) for adult males in the US and Brazil. The stronger positive relationship for the Brazilian population is particularly striking, and is likely driven by a relatively worse health and nutritional distribution there. ${ }^{13}$

The lower panel of Figure 5 shows this relationship holds across education levels, suggesting that the positive effect health has on earning potential exists independently of education human capital. In fact, there is also extensive biomedical evidence pointing to the effects of health, particularly child health and nutrition early in life, on educational attainments. For example, Seshadri and Gopaldas (1989), find that iron deficiency significantly affects children's cognitive development and school performance in India. In another study, Kvalsvig et al. (1991), present evidence on how parasitic infections combine with malnourishment to impair cognitive processes. ${ }^{14}$ Moreover, disease-induced disabilities and frequent illnesses are key causes of school absenteeism and high dropout rates in developing countries (World Bank, 1993).

In this section we alter our basic framework to incorporate such effects of health investment. In particular, we allow health investment in the form of better nutrition and personal care to lower an individual's mortality risk, as well as increase her labor productivity. When education and health are complementary inputs determining a worker's productivity, we show that improved health results in greater investment in education, consistent with the microeconometric and biomedical evidence.

To be more specific, suppose that an individual works in both periods of her life, being endowed with time endowments of one unit in each period. Individuals do not differ in their education or health capital in the first period, but their labor income in the subsequent period depends on human capital investment earlier in life. For an individual who invests $h_{t}$ in health and $e_{t}$ in her education, second-period income is given by $\bar{w}\left[1+\zeta\left(e_{t}, h_{t}\right)\right]$, where $\zeta$ relates health and education to a worker's productivity and satisfies $\zeta(0, h)=\zeta(e, 0)=0$.

\footnotetext{
${ }^{13}$ This effect of nutrition on productivity can be quantitatively large. Strauss (1986), for instance, estimates the elasticity of farm output with respect to calorie consumption in Sierra Leone to be about 0.33.

${ }^{14}$ See Behrman (1996) for a critical review of this literature.
} 
Preferences are identical to those given by (7). Individuals now maximize their expected lifetime utility (1) subject to the two budget constraints

$$
\begin{aligned}
c_{t}^{t} & =\bar{w}+W_{t}-s_{t}-h_{t}, \\
c_{t+1}^{t} & =\bar{w}\left[1+\zeta\left(e_{t}, h_{t}\right)\right]+R s_{t}-b_{t+1} .
\end{aligned}
$$

The effect health and education have on intergenerational wealth dynamics depends on the nature of the $\zeta$ function. Ray and Streufert (1993) consider a similar setup (without educational investment) where $\zeta$ is non-convex: at low levels of health, higher nutritional intakes result in increasingly higher productivity. This would result in nutrition-based efficiency wages and in equilibrium unemployment among the poor and malnourished. However, as Strauss and Thomas (1998) point out, empirical support for such an efficiency wage hypothesis is weak.

We work, instead, with a convex technology for human capital and assume that $\zeta$ is given by

$$
\zeta\left(e_{t}, h_{t}\right)=a e_{t}^{\alpha} h_{t}^{1-\alpha},
$$

where $a>0$ and $\alpha \in(0,1)$. Individuals choose the vector $\left(s_{t}, e_{t}, h_{t}, b_{t+1}\right)$ to maximize lifetime utility, necessary and sufficient conditions for which are given by

$$
\begin{aligned}
c_{t+1}^{t} & =\left[\phi\left(h_{t}\right) R\right]^{1 / \sigma} c_{t}^{t}, \\
c_{t+1}^{t} & =\left[\phi\left(h_{t}\right) \alpha A\left(\frac{h_{t}}{e_{t}}\right)^{1-\alpha} R\right]^{1 / \sigma} c_{t}^{t} \\
(1-\sigma)\left(c_{t}^{t}\right)^{-\sigma} & =\left[\phi^{\prime}\left(h_{t}\right)\left[\left(c_{t+1}^{t}\right)^{1-\sigma}+\theta b_{t+1}^{1-\sigma}\right]+A(1-\sigma)(1-\alpha) \phi\left(h_{t}\right)\left(\frac{e_{t}}{h_{t}}\right)^{\alpha}\left(c_{t+1}^{t}\right)^{-\sigma}\right] \\
b_{t+1} & =\beta c_{t+1}^{t},
\end{aligned}
$$

where $A \equiv a \bar{w}$. We follow our previous strategy in characterizing optimal health investment. Note first that (22) and (23) imply that returns to savings $(R)$ and educational investment $\left(\zeta_{e}\right)$ are equalized, so that,

$$
e_{t}=\left[\frac{\alpha A}{R}\right]^{1 /(1-\alpha)} h_{t},
$$

implying that healthier individuals invest more in education.

Now using (25) and (26) in (24), we obtain

$$
c_{t+1}^{t}=\gamma_{0} h_{t},
$$

where

$$
\gamma_{0} \equiv \frac{1-\sigma}{\varepsilon_{\phi}}\left[\frac{1}{1+\beta}\right]\left[R-A(1-\alpha)\left(\frac{\alpha A}{R}\right)^{\alpha /(1-\alpha)}\right]
$$


Evidently $c_{t+1}^{t}$ is positive as long as

$$
R>(\alpha)^{\alpha}(1-\alpha)^{1-\alpha} A,
$$

which we shall henceforth maintain. This assumption is necessary to derive any meaningful solution to the optimization problem and can be reduced to an intuitive condition.

For the Cobb-Douglas human capital technology above, the elasticities of labor productivity with respect to education and health are simply $\alpha$ and $1-\alpha$ respectively. Assumption 2 can then be written out as

$$
R>\left[\frac{e \zeta_{e}}{\zeta}\right]^{\alpha}\left[\frac{h \zeta_{h}}{\zeta}\right]^{1-\alpha} A=\left(\zeta_{e}\right)^{\alpha}\left(\zeta_{h}\right)^{1-\alpha}
$$

As noted above, we also have $R=\zeta_{e}$ at an interior optimum. Hence the inequality above simplifies to

$$
R=\zeta_{e}>\left(\zeta_{e}\right)^{\alpha}\left(\zeta_{h}\right)^{1-\alpha} \Leftrightarrow R=\zeta_{e}>\zeta_{h} .
$$

To see why this condition is required, note that each of the first order conditions (22) - (24) equates the marginal cost of foregoing current consumption to the marginal benefit from alternative means of investment. It is clear that if the restriction above is not satisfied, then the marginal benefit from health investment (which comprises of the utility gains from longer lifetimes, in addition to $\zeta_{h}$ ) will dominate gains from saving and educational investment. Individuals would not invest in education or by saving in that case.

From the second-period budget constraint, we obtain using (27),

$$
s_{t}=\gamma_{1} h_{t}-\frac{\bar{w}}{R}
$$

where we have defined $\gamma_{1} \equiv\left[(1+\beta) \gamma_{0}-A(\alpha A / R)^{\alpha /(1-\alpha)}\right] / R$. Likewise, from (22) and (27),

$$
c_{t}^{t}=\gamma_{2} h_{t}\left[\phi\left(h_{t}\right)\right]^{-1 / \sigma}
$$

where $\gamma_{2} \equiv(R)^{-1 / \sigma} \gamma_{0}$. Using these relations in the first-period budget constraint gives us

$$
h_{t}=W_{t}+\left[\frac{1+R}{R}\right] \bar{w}-\gamma_{1} h_{t}-\gamma_{2} h_{t}\left[\phi\left(h_{t}\right)\right]^{-1 / \sigma}-A\left[\frac{\alpha A}{R}\right]^{\alpha /(1-\alpha)} h_{t}
$$

or,

$$
\Pi\left(h_{t}\right) \equiv \gamma_{3} h_{t}+\gamma_{2} h_{t}\left[\phi\left(h_{t}\right)\right]^{-1 / \sigma}=W_{t}+\left[\frac{1+R}{R}\right] \bar{w},
$$

where $\gamma_{3} \equiv 1+\gamma_{1}+(\alpha A / R)^{1 /(1-\alpha)}>0$ and $\gamma_{2}>0$. As before, this equation implicitly characterizes health investment as a function of wealth: 
Proposition 2 Optimal health investment, $h=\nu(W)$, implicitly defined by equation (30), satisfies the following properties:

(i) $\nu(0)>0$ whenever $\bar{w}>0$,

(ii) $\partial \nu(W) / \partial W \geq 0$ with $\lim _{W \rightarrow \infty} \partial \nu(W) / \partial W=0$, and

(iii) $\partial^{2} \nu(W) / \partial W^{2}<0$ for $\sigma<\varepsilon_{\phi(\nu(W))}, \partial^{2} \nu(W) / \partial W^{2}>0$ for $\sigma>\varepsilon_{\phi(\nu(W))}$, while $\lim _{W \rightarrow \infty} \partial^{2} \nu(W) / \partial W^{2}=0$.

Proof. See Appendix B.

Lemma 1 From Propositions 1 and 2, it follows that

$$
\frac{\partial \nu(W)}{\partial W}>\frac{\partial \eta(W)}{\partial W}
$$

for any wealth level, $W$.

Proof. See Appendix C.

Optimal bequests and savings are now given by

$$
b_{t+1}=\left[\frac{\beta}{1+\beta}\right]\left[\frac{1-\sigma}{\varepsilon_{\phi}}\right] R h\left(W_{t}\right) \equiv \Phi_{1}\left(W_{t}\right)
$$

and

$$
s_{t}=\left[\frac{1-\sigma}{\varepsilon_{\phi}}\right] h\left(W_{t}\right)-\frac{\bar{w}}{R} \equiv \Phi_{2}\left(W_{t}\right),
$$

where $\Phi_{1}$ and $\Phi_{2}$ are both increasing functions of wealth.

Once again these individual wealth transition mappings determine the evolution of the wealth distribution as follows:

$$
W_{t+1}^{i}=\Phi\left(W_{t}^{i}\right)= \begin{cases}\Phi_{1}\left(W_{t}^{i}\right), & \text { with probability } \phi\left(h\left(W_{t}^{i}\right)\right), \\ \Phi_{2}\left(W_{t}^{i}\right), & \text { otherwise }\end{cases}
$$

given the initial distribution $G_{0}$.

This model of human capital investment gives two predictions relative to the benchmark model analyzed in section 2 above. A comparison of Propositions 1 and 2 shows that conditions under which long-run persistence in health and income status obtain are more-or-less similar in both models. The difference comes from noting the implications of Lemma 1: corresponding to any wealth level, health investment is now greater because it brings in additional benefits through labor productivity. But since health investments now rise faster 
with wealth accumulation, $\sigma$ will exceed $\varepsilon_{\phi}$ at lower levels of wealth than before. ${ }^{15}$ In other words, it is likelier now that we will obtain long-run persistence of the kind illustrated by Figure 4.

Even when such non-ergodicity does not result, as in Figure 2 for example, Lemma 1 implies that intended and unintended bequest lines are steeper than before. Accordingly, convergence to the unique stationary distribution will be slower, and we expect to observe significantly higher short-term correlation in health and wealth across generations in a particular dynasty than before. In both instances, productivity-enhancing health investments serve to amplify the persistence of intergenerational health and economic status relative to the benchmark model.

\section{Extensions}

In the analyses so far health outcomes depend only on private health investment. Moreover, due to the 'small open economy' assumption, standard channels of capital accumulation are absent. Both assumptions have considerably simplified the analysis by allowing aggregate wealth dynamics to mimic the time-invariant dynastic wealth evolution depicted by equation (19) or (33). In this section we briefly consider what happens when we allow for meaningful interactions across economic agents. Two scenarios are especially relevant: when there are externalities in health investment, and when capital accumulation affects factor prices.

Human capital formation is typically associated with externalities (Galor and Tsiddon, 1997). In the context of health, private expenditures in sanitation, personal hygiene, vaccination and nourishment can have significant public health effects through their impact on the incidence of diseases and the population size at risk of contacting these diseases. When such externalities are present, the survival probability for a particular individual depends not only her health expenditure incurred privately, but also on the average level of health investment undertaken in her community.

Suppose for a generation- $t$ individual, the probability of survival is now given by $\hat{\phi}\left(h_{t}^{i}\right)=$ $\varphi\left(\bar{h}_{t}\right) \phi\left(h_{t}^{i}\right)$, where $\bar{h}_{t}=\int_{0}^{\infty} \eta\left(W_{t}^{i}\right) d G_{t}(W)$ is average health investment at time $t .{ }^{16}$ Health externalities are assumed to generate a simple threshold effect

$$
\varphi(\bar{h})= \begin{cases}\varphi_{0}, & \text { if } \bar{h}<\tilde{h} \\ \varphi_{1}, & \text { if } \bar{h} \geq \tilde{h}\end{cases}
$$

\footnotetext{
${ }^{15}$ That is, if $\sigma=\varepsilon_{\phi\left(h_{c}\right)}$, and since $\nu^{\prime}(W)>\eta^{\prime}(W)$ for all $W$, we must have, $\nu^{-1}\left(h_{c}\right)<\eta^{-1}\left(h_{c}\right)$.

${ }^{16}$ The size of each generation has been normalized to unity.
} 
with $\varphi_{1}>\varphi_{0}$, similar to education capital externalities analyzed by Galor and Tsiddon (1997). More generally one would expect these externalities to be increasing, at least over a range, with average health status and/or investment in the economy. The expected bequest line for the $i$-th dynasty is now represented by

$$
\hat{\Psi}^{E}\left(W_{t}^{i}\right) \equiv \hat{\phi}\left(\eta\left(W_{t}^{i}\right)\right) \hat{\Psi}_{1}\left(W_{t}^{i}\right)+\left[1-\hat{\phi}\left(\eta\left(W_{t}^{i}\right)\right)\right] \hat{\Psi}_{2}\left(W_{t}^{i}\right) .
$$

It is easy to see that this expected bequest line will now comprise of two disjoint segments, one corresponding to $\varphi\left(\bar{h}_{t}\right)=\varphi_{0}$, and the other to $\varphi\left(\bar{h}_{t}\right)=\varphi_{1}$, with the former lying below the latter. Staring from an initial wealth level $W_{0}^{i}$, dynasty $i$ moves along the lower expected bequest line as long as $\bar{h}_{t}<\tilde{h}$, and jumps to the upper one when $\bar{h}_{t}$ exceeds $\tilde{h}$.

Allowing for this kind of threshold externalities in the benchmark model of Section 2 immediately enhances the possibility of a poverty trap, even when intended and accidental bequest lines are 'well-behaved'. To see how, suppose in the absence of externality the wealth dynamics is represented by Figure 2, so that all dynasties asymptotically converge to $\bar{W}$ irrespective of initial wealth. Let us now introduce a threshold effect as specified above and assume that for the initial distribution, we have

$$
\bar{h}_{0}=\int_{0}^{\infty} \eta\left(W_{0}^{i}\right) d G_{0}(W)<\tilde{h},
$$

that is, all the dynasties are initially on the lower the expected bequest line, corresponding to $\varphi_{0}$. If $\varphi_{0}$ is small enough, this line, which follows a convex-concave pattern (see Section 2), would have three points of intersection with the $45^{\circ}$ line, $\left(\bar{W}_{L}^{3}, \bar{W}_{L}^{2}, \bar{W}_{L}^{1}\right)$. On the other hand, if $\varphi_{1}$ is sufficiently large, the upper expected bequest line corresponding to $\varphi_{1}$ intersects the $45^{\circ}$ line only once, at $\bar{W}_{H}$. Figure 6 depicts such a scenario.

If the average health capital in this economy remains below the threshold level for all $t$, then of course the economy remains on the lower expected bequest line forever, and wealth dynamics is similar to that illustrated by Figures 3 and 4 . Conversely, if over time the average health capital becomes large enough, all dynasties eventually move to the upper expected bequest line. There is no long-run polarization and everyone enjoys the same healthy state irrespective of their initial wealth. Whether the economy remains stuck at the lower expected bequest line with polarization, or can escape the poverty trap and move to the upper expected bequest line (leaving everybody better-off in the long run) depends crucially on the initial health and wealth distribution.

Note the critical role played by initial distribution here: it now determines not just the degree of polarization, but the very possibility of polarization. It is obvious that the economy 
would escape the poverty trap if a sufficient number of people enjoy health greater than $\tilde{h}$, so that the average health capital exceeds this threshold. Let the steady state health levels associated with the lower expected bequest line be $\eta\left(\bar{W}_{L}^{3}\right)$ and $\eta\left(\bar{W}_{L}^{1}\right)$ respectively, and let $\eta\left(\bar{W}_{L}^{3}\right)<\tilde{h}<\eta\left(\bar{W}_{L}^{1}\right)$. It then follows that the greater is initial inequality, the lower is the proportion of people who eventually attain a health capital greater than $\tilde{h}$, and therefore lower are the chances for this economy to escape the poverty trap. Thus inequality bites in more than one sense.

The mechanism elaborated here assumes special significance in the context of developing countries, particularly those in the tropics, characterized by large-scale incidence of infectious diseases (World Bank, 1993, Murray and Lopez, 1996). Indeed, the mechanism suggests that even controlling for income distribution, exogenous health distributions (working through the externality) could give rise to Pareto inferior outcomes that leave everyone worse-off in the long run (compared to the alternative scenario). This indicates a key role for public health policy in these countries, a point we return to in the concluding section.

A second kind of interaction among economic agents operates through the effect of capital accumulation on equilibrium factor prices. In a closed economy version of the model presented in section 2, wages and interest rates would depend upon the economy's capital-labor ratio, and thus, on the entire wealth distribution at any point in time. Aggregate wealth dynamics would no longer be a simple replica of individual wealth dynamics as we would have to take into account the effects of endogenously determined wage and interest rates on wealth accumulation and investment.

First consider how investment contributes to the accumulation of physical capital. Recall that only the savings of individuals who survive into old-age are invested. The aggregate physical capital stock is hence determined according to:

$$
K_{t+1}=\int \phi\left(W_{t}^{i}\right) s\left(W_{t}^{i}\right) d G_{t} .
$$

Since both the young and old work, and since corresponding to any wealth level $W_{t}^{i}$ a fraction $\phi\left(W_{t}^{i}\right)$ survive into old-age (by the law of large numbers), capital per worker is given by

$$
k_{t+1}=\frac{K_{t+1}}{1+\int \phi\left(W_{t}^{i}\right) d G_{t}} .
$$

Evidently the wealth distribution $G_{t}$ determines factor prices $\left(w_{t+1}, r_{t+1}\right)$ via this equation. In the process, it impacts the future wealth distribution $G_{t+1}$ through a dynamic system similar to (33) above. The resulting interplay between factor prices and the wealth distribution can give rise to complicated non-linear dynamics, as noted by Banerjee and Newman 
(1993) and Aghion and Bolton (1997). Without going into the specifics of such problems, we only conjecture to what extent results presented earlier generalize to this case.

Here too the initial wealth distribution turns out to be of significance. Higher are typical wealth levels, the greater is health investment. Longer lifespans induce people to save and invest more, and thus, lead to faster accumulation of capital stocks. When a greater number of individuals survive into old-age, it increases the size of the labor force. This tends to dilute the effects of capital accumulation by exerting downward pressure on the capital intensity of production. Under the assumption that the investment effect dominates, a more favorable wealth distribution leads to high $k$, and thus, higher wages, $w$. Rising wages tend to push up poorer individuals faster by allowing for greater health (and educational) investment.

A second channel works in tandem: capital deepening lowers returns to saving and investment. Relative to physical capital investment, health and education become more attractive investment opportunities (see equation (26)), eliciting even greater human capital investments.

Both effects are, however, predicated on a favorable wealth distribution, that is, a distribution that yields dynamics similar to Figure 2. If the dynamics corresponding to the initial distribution $G_{0}$, for instance, were to look like Figure 4, factor price movements might not mitigate tendencies for parental status to persistently affect health investment in the progeny. Specifically, as dynasties move either to the lower or upper stationary distributions, there may be a tendency for the non-ergodic dynamics to be reinforced - with a relatively unequal wealth distribution, fewer people save and invest as much as is required to significantly increase wages and lower interest rates, thereby hindering upward mobility among the poorer households.

\section{Conclusion}

We have analyzed in this paper a model of intergenerational mobility operating through the accumulation of health capital. We show that initial health inequality can be a key factor in explaining the observed persistence in wealth and income inequality across households. We underline the crucial role of health capital in the process of development. Unlike other forms of human capital, the role of health capital is quite unique: not only does it generate positive externalities, it also affects individuals' mortality risks, thereby altering their incentives. As we demonstrate here, this latter aspect of health capital formation has important implications for intergenerational mobility and equality. 
The source of persistence highlighted here is especially important for developing economies. Though medical innovations in the past few decades have substantially reduced the infant and child mortality rate in these countries, adult mortality rates in much of the developing world continue to be quite high. Adult mortality risk, the probability of a typical 15-year old dying before age 60, in Sub-Saharan Africa, for instance, is about three times higher than in the established market economies (World Bank, 1993, Table A.5). Hence persistent poverty in these countries can be attributable to a large extent to the associated higher mortality risks.

The paper calls for a key role to be played by the public health system. Apart from providing cheap health care to the poor, public health expenditure in developing countries can significantly reduce mortality risks by providing a healthier environment in terms of better hygiene, sanitation, availability of clinical facilities etc.

The composition of public health expenditure is of utmost importance in this context. The efficiency of a public health system depends very much on how broad its reach is. It is here that many developing countries continue to face serious problems. As the World Bank (1993) notes, while the economically backward classes tend to suffer from usually treatable infectious diseases, public money is often spent, instead, on relatively 'more expensive' disease treatments (cancer surgery, for example) that mainly benefits the wealthy. Government spending on health goes disproportionately to the rich in the form of free or cheap health care and insurance subsidies. In Indonesia, for example, "government subsidies to health for the richest 10 percent of households in 1990 were ... almost three times the subsidies going to the poorest 10 percent" (World Bank, 1993, p. 4). In addition, the quality of care available for the poor is typically low.

In the presence of inefficient public health systems, income remains the underlying determinant of adult mortality rates, especially for the poor and malnourished. Apart from quality of life considerations, the economic consequences of health inequality that we have isolated in this paper provides a strong cause for public health systems to devote more resources toward the poor. 


\section{References}

[1] Aghion, Philippe and Patrick Bolton (1997), "A Theory of Trickle-Down Growth and Development", Review of Economic Studies, vol. 64, pp. 151-172.

[2] Andreoni, James (1989), "Giving with Impure Altruism: Applications to Charity and Ricardian Equivalence", Journal of Political Economy, vol. 97, pp. 1447-1458.

[3] Banerjee, Abhijit and Andrew Newman (1993), "Occupational Choice and the Process of Development", Journal of Political Economy, vol. 101, pp. 274-298.

[4] Behrman, Jere R. (1993), "The Economic Rationale for Investing in Nutrition in Developing Countries", World Development, vol. 21, pp. 1749-71.

[5] Behrman, Jere R. (1996), "The Impact of Health and Nutrition on Education", The World Bank Research Observer, vol. 11, pp. 23-37.

[6] Benabou, Roland (1996), "Heterogeneity, Stratification, and Growth: Macroeconomic Implications of Community Structure and School Finance", American Economic Review, vol. 86, pp. 584-609.

[7] Chakraborty, Shankha (1999), "Public Health, Longevity and Economic Growth", PhD Dissertation (Chapter 3), University of California at Los Angeles.

[8] Deaton, Angus (2003), "Health, Inequality and Economic Development", Journal of Economic Literature, vol. XLI (1), pp. 113-158.

[9] Durlauf, Steven (1996), "A Theory of Persistent Inequality", Journal of Economic Growth, vol. 1, pp. 75-95.

[10] Fogel, Robert W. (1994), "Economic Growth, Population Theory and Physiology: The Bearing of Long-Term Processes on the Making of Economic Policy", American Economic Review, vol. 84, pp.369-393.

[11] Fogel, Robert W. (1997), "New Findings on Secular Trends in Nutrition and Mortality: Some implications for population theory", in M. Rosenzweig and O. Stark eds., Handbook of Population and Family Economics, vol. 1A, Elsevier Science, The Netherlands.

[12] Freeman, Scott (1996), "Equilibrium Income Inequality among Identical Agents", Journal of Political Economy, vol. 104, pp. 1047-1064.

[13] Galor, Oded and Daniel Tsiddon (1997), "The Distribution of Human Capital and Economic Growth," Journal of Economic Growth, vol. 2, pp. 93-124. 
[14] Galor, Oded and Joseph Zeira (1993), "Income Distribution and Macroeconomics," Review of Economic Studies, vol. 60, pp. 35-52.

[15] Ghatak, Maitreesh and Neville Nien-Huei Jiang (2002), "A Simple Model of Inequality, Occupational Choice and Development", Journal of Development Economics, vol. 69, pp. 205-226.

[16] Kalemli-Ozcan, Sebnem, Ryder, Harl and David N. Weil (2000), "Mortality Decline, Human Capital Investment and Economic Growth", Journal of Development Economics, vol. 62, pp. 1-23.

[17] Kvalsig, J. D., Cooppan, R. M., and K. J. Connolly (1991), "The Effects of Parasitic Infections on Cognitive Processes in Children," Annals of Tropical Medicine and Parasitology, vol. 85, pp. 551-568.

[18] Lantz, Paula M., House, James S., Lepkowski, James M., Williams, David R., Mero, Richard P. and Jieming Chen (1998), "Socioeconomic Factors, Health Behaviours, and Mortality", Journal of the American Medical Association, vol. 279, pp. 17031708.

[19] Lopez, Alan D. (1993), "Causes of Death in Industrial and Developing Countries: Estimates for 1985-1990", in Dean T. Jamison, W. Henry Mosley, Anthony R. Measham and Jose Luis Bobadilla eds., Disease Control Priorities in Developing Countries, Oxford University Press, Washington D.C..

[20] Menchik, Paul (1993), "Economic Status as a Determinant of Mortality among Black and White Older Men: Does Poverty Kill?", Population Studies, vol 47, pp. 427-436.

[21] Menchik, Paul and Martin David (1983), "Income Distribution, Lifetime Savings, and Bequests", American Economic Review, vol 73, pp. 672-690.

[22] Moav, Omer (2002), "Income Distribution and Macroeconomics: the Persistence of Inequality in a Convex technology Framework", Economics Letters, vol. 75, pp. 187192.

[23] Moaz, Yishay and Omer Moav (1999), "Intergenerational Mobility and the Process of Development", Economic Journal, vol. 109, pp. 677-697.

[24] Mulligan, Casey (1997), Parental Priorities and Economic Inequality, University of Chicago Press, Chicago.

[25] Murray, Christopher J. L., and Alan D. Lopez (1996), The Global Burden of Disease, Harvard University Press for the World Bank, World Health Organization and the 
Harvard School of Public Health, Cambridge, Mass., U.S.A.

[26] Piketty, Thomas (1997), "The Dynamics of the Wealth Distribution and the Interest Rate with Credit Rationing", Review of Economic Studies, vol. 64, pp. 173-189.

[27] Piketty, Thomas (2000), "Theories of Persistent Inequality and Intergenerational Mobility", in Anthony Atkinson and Francois Bourguignon eds., Handbook of Income Distribution, vol. 1, Elsevier Science, Amsterdam.

[28] Ray, Debraj and Peter A. Streufert (1993), "Dynamic Equilibria with Unemployment due to Undernourishment", Economic Theory, vol. 3, pp. 61-85.

[29] Seshadri, Subadra and Tara Gopaldas (1989), "Impact of Iron Supplementation on Cognitive Functions in Preschool and School-Aged Children: The Indian Experience," The American Journal of Clinical Nutrition, vol. 50, pp. 675-86.

[30] Solon, Gary (1993), "Intergenerational Income Mobility in the United States", American Economic Review, vol. 82, pp. 393-408.

[31] Solon, Gary (2002), "Cross-Country Differences in Intergenerational Earnings Mobility," Journal of Economic Perspectives, Summer, pp. 59-66.

[32] Sorlie, P. D., Backlund, E. and J. B. Keller (1995), "US Mortality by Economic, Demographic and Social Characteristics: The National Longitudinal Mortality Study", American Journal of Public Health, vol. 85, pp. 949-956.

[33] Stokey Nancy (1996), "Shirtsleeves to Shirtsleeves: The Economics of Social Mobility", The Nancy Schwartz Memorial Lecture, reprinted in Donald Jacobs, Ehud Kalai and Morton Kamien eds., Frontiers of Research in Economic Theory, Cambridge University Press, Cambridge, UK.

[34] Strauss, John (1986), "Does Better Nutrition Raise Farm Productivity?", Journal of Political Economy, vol. 94, pp. 297-320.

[35] Strauss, John and Duncan Thomas (1998), "Health, Nutrition and Economic Development", Journal of Economic Literature, vol. 36 (June): 766-817.

[36] Strauss, John and Duncan Thomas (2000), "Health and Wages: Evidence on Men and Women in Urban Brazil", in Pranab Bardhan and Christopher Udry eds., Readings in Development Microeconomics, vol. 2, MIT Press, Cambridge, MA.

[37] Wilkinson, Richard (1996), Unhealthy Societies: the Afflictions of Inequality, Routledge, New York. 
[38] World Bank (1993), World Development Report: Investing in Health, Oxford University Press, New York.

[39] World Bank (2003), Country Reports on Health, Nutrition, Population, and Poverty, available at http://www.worldbank.org/poverty/health/index.htm

[40] Yaari, Menahem E. (1965), "Uncertain Lifetime, Life Insurance, and the Theory of the Consumer", Review of Economic Studies, vol 32, pp. 137-50.

[41] Zimmerman, David (1992), "Regression toward Mediocrity in Economic Stature", American Economic Review, vol. 82, pp. 408-429. 


\section{Appendix}

\section{Appendix A: Proof of Proposition 1}

Equation (14) defines optimal health investment as $h_{t}=\eta\left(W_{t}\right)$. From Figure 1, as long as $\bar{w}>0, \eta(0)>0$. Totally differentiating (14) we get

$$
\frac{\partial \eta}{\partial W}=\frac{1}{\mu_{0}+\mu_{1} \phi^{-1 / \sigma}\left(\sigma-\varepsilon_{\phi}\right) / \sigma}
$$

and

$$
\frac{\partial^{2} \eta}{\partial W^{2}}=\left[\frac{1}{\mu_{0}+\mu_{1} \phi^{-1 / \sigma}\left(\sigma-\varepsilon_{\phi}\right) / \sigma}\right]^{2} \frac{\sigma-\varepsilon_{\phi}}{\sigma^{2}} \mu_{1} \phi^{-1 / \sigma-1} \phi^{\prime} \frac{\partial h}{\partial W} .
$$

Clearly when $\sigma>\varepsilon_{\phi}, \partial \eta / \partial W>0$ and $\partial^{2} \eta / \partial W^{2}>0$. When $\sigma<\varepsilon_{\phi}, \partial \eta / \partial W<0$ for $h<\tilde{h}$ and $>0$ for $h>\tilde{h}$, where $\tilde{h} \equiv \phi^{-1}\left[\left\{\left(\mu_{1} / \mu_{0}\right)\left(\varepsilon_{\phi}-\sigma\right) / \sigma\right\}^{\sigma}\right]$. Following arguments in the text and Figure 1, the optimal investment choice $\eta(W)>\widetilde{h}$. This means, even if $\sigma<\varepsilon_{\phi}$, $\partial \eta / \partial W>0$. But in this case $\partial^{2} \eta / \partial W^{2}<0$. Finally, note that since $\phi^{\prime \prime} \leq 0$, we must have $\lim _{W \rightarrow \infty} \partial \eta / \partial W=0=\lim _{W \rightarrow \infty} \partial^{2} \eta / \partial W^{2}$.

\section{Appendix B: Proof of Proposition 2}

Straightforward differentiation of (30) gives us

$$
\frac{\partial \nu}{\partial W}=\frac{1}{\gamma_{3}+\gamma_{2} \phi^{-1 / \sigma}\left(\sigma-\varepsilon_{\phi}\right) / \sigma}
$$

and

$$
\frac{\partial^{2} \nu}{\partial W^{2}}=\left[\frac{1}{\gamma_{3}+\gamma_{2} \phi^{-1 / \sigma}\left(\sigma-\varepsilon_{\phi}\right) / \sigma}\right]^{2} \frac{\sigma-\varepsilon_{\phi}}{\sigma^{2}} \gamma_{2} \phi^{-1 / \sigma-1} \phi^{\prime} \frac{\partial h}{\partial W} .
$$

As for Proposition 1, when $\sigma>\varepsilon_{\phi}, \partial \nu / \partial W>0$ and $\partial^{2} \nu / \partial W^{2}>0$. Similarly, when $\sigma<\varepsilon_{\phi}$, $\partial \nu / \partial W>0$, but $\partial^{2} \nu / \partial W^{2}<0$. Concavity of $\phi$ ensures that both the first and second derivatives of $\nu(W)$ go to zero as $W \rightarrow \infty$.

\section{Appendix C: Proof of Lemma 1}

From (A.1) above, $\partial \eta\left(W_{t}\right) / \partial W_{t}$ is inversely proportional to $\mu_{0}+\mu_{1} \phi_{t}^{-1 / \sigma}\left(\sigma-\varepsilon_{\phi}\right) / \sigma$. From (A.2), $\partial \nu\left(W_{t}\right) / \partial W_{t}$ is inversely proportional to $\gamma_{3}+\gamma_{2} \phi_{t}^{-1 / \sigma}\left(\sigma-\varepsilon_{\phi}\right) / \sigma$. A simple comparison shows that $\mu_{0}>\gamma_{3}$, while $\mu_{1}>\gamma_{2}$ (since $\alpha<1$ ). It follows that optimal health investment rises more steeply with wealth when individuals invest in labor productivity than when they do not, that is, $\nu^{\prime}(W)>\eta^{\prime}(W)$. 

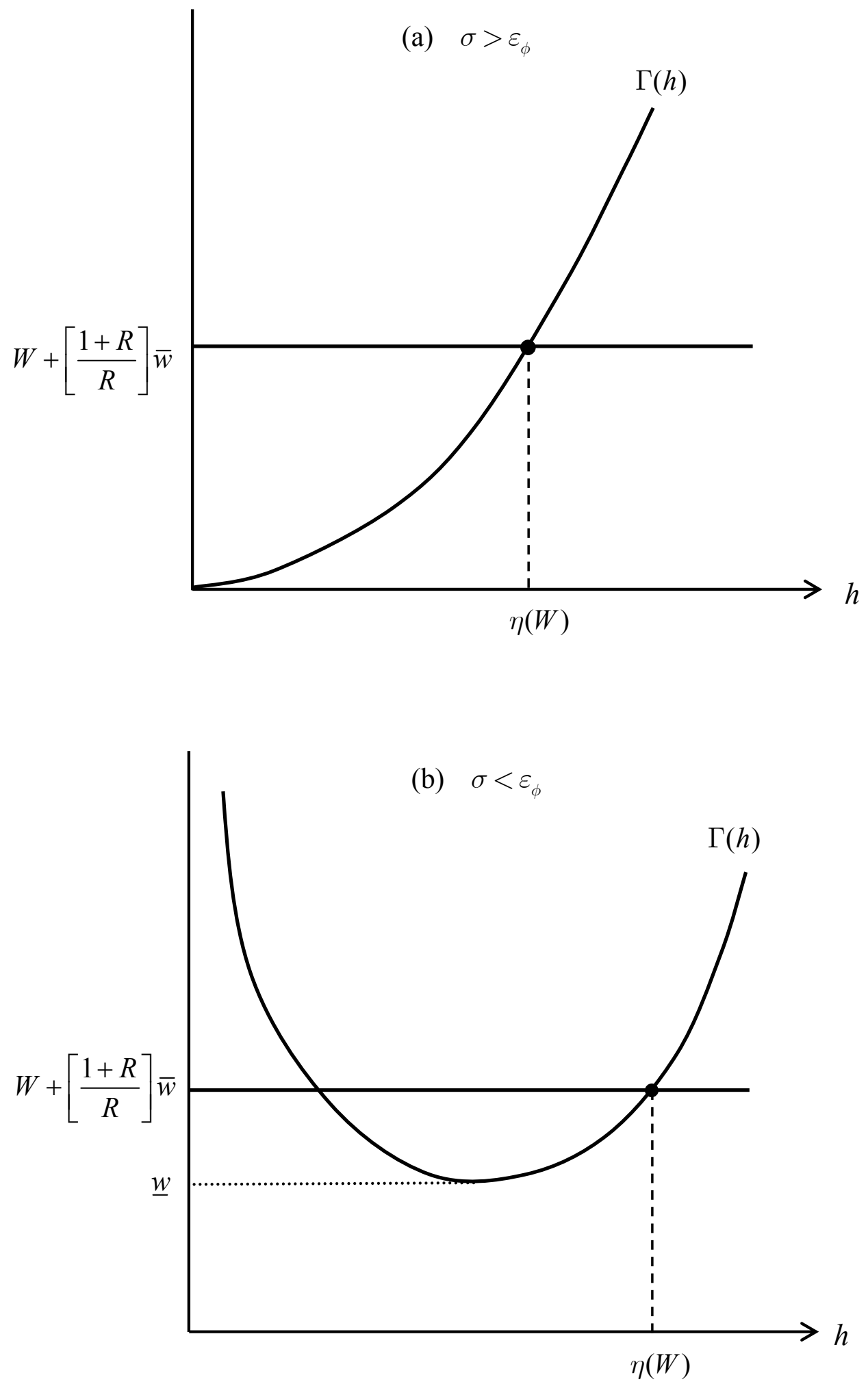

Figure r: Optimal Health Investment 

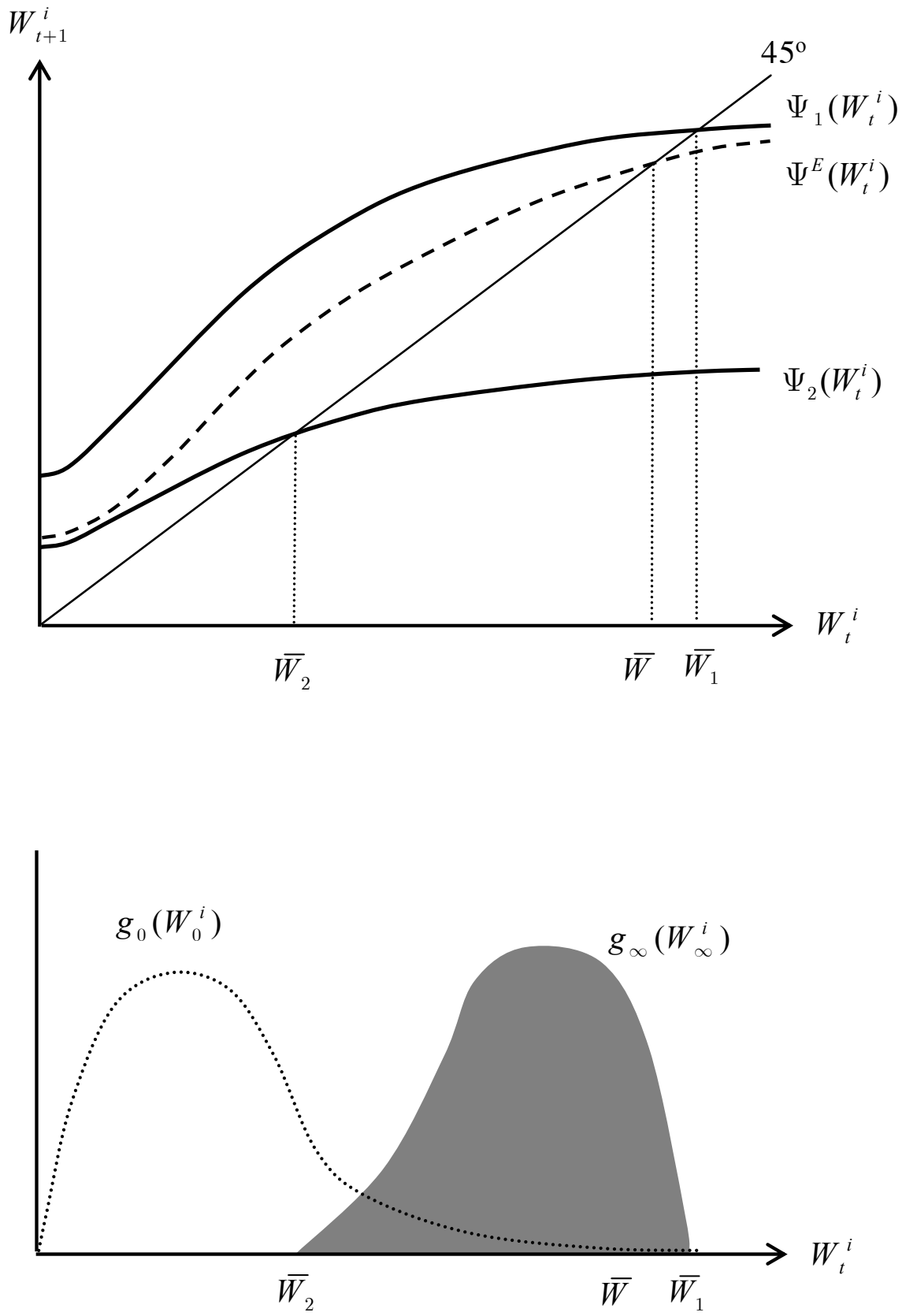

Figure 2: Wealth Dynamics with Convergence 

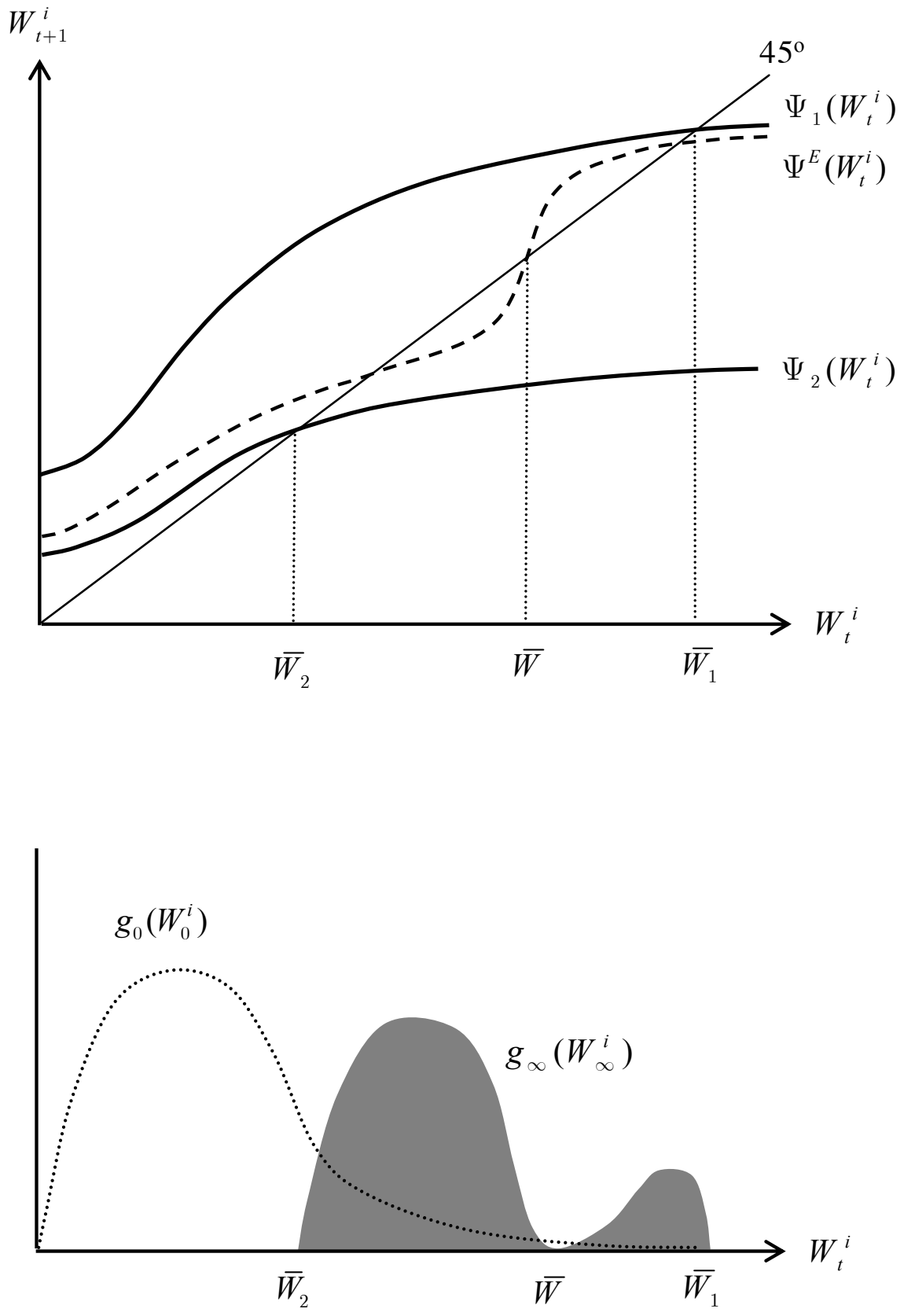

Figure 3: Wealth Dynamics with some Polarization 

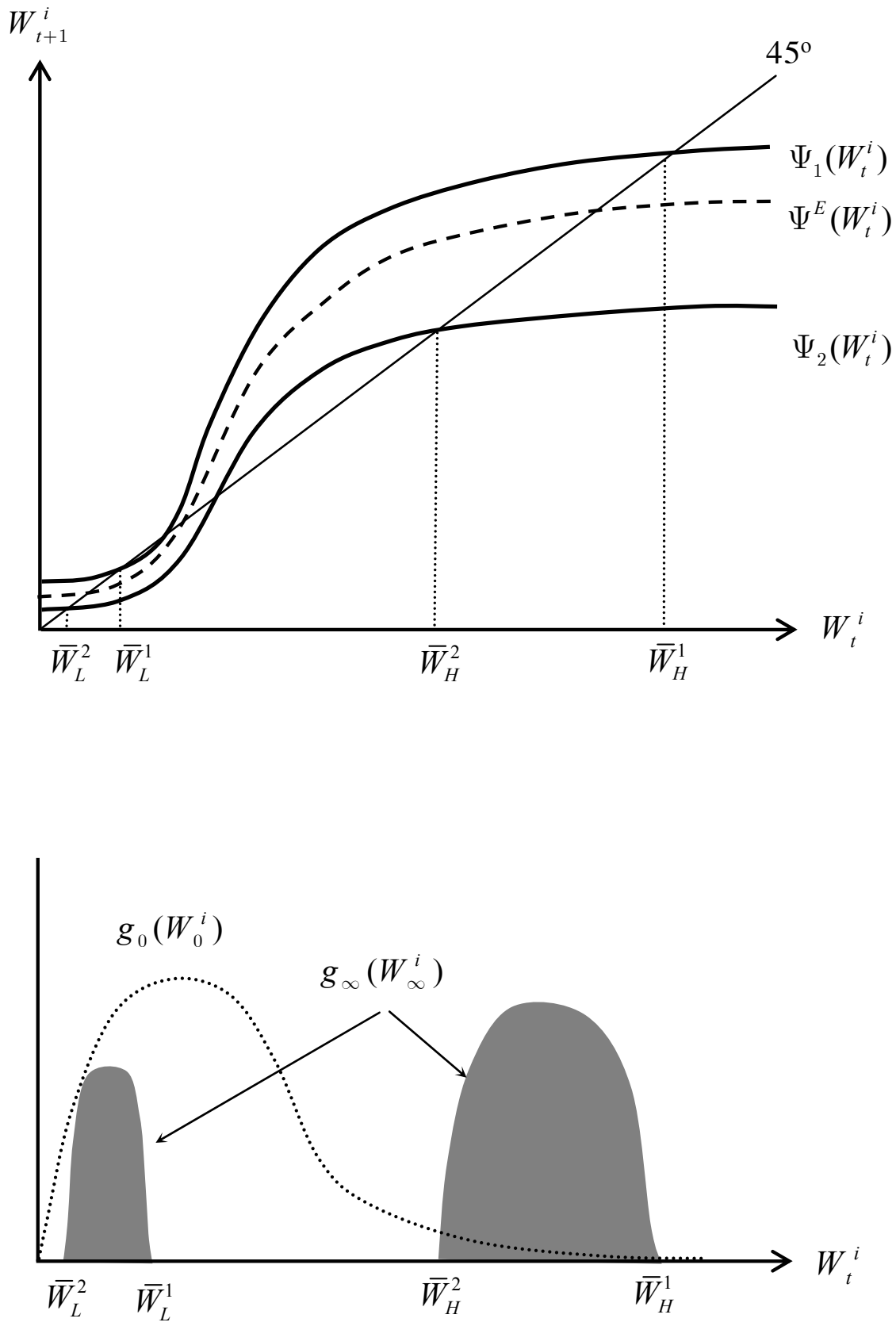

Figure 4: Wealth Dynamics with extreme Polarization 

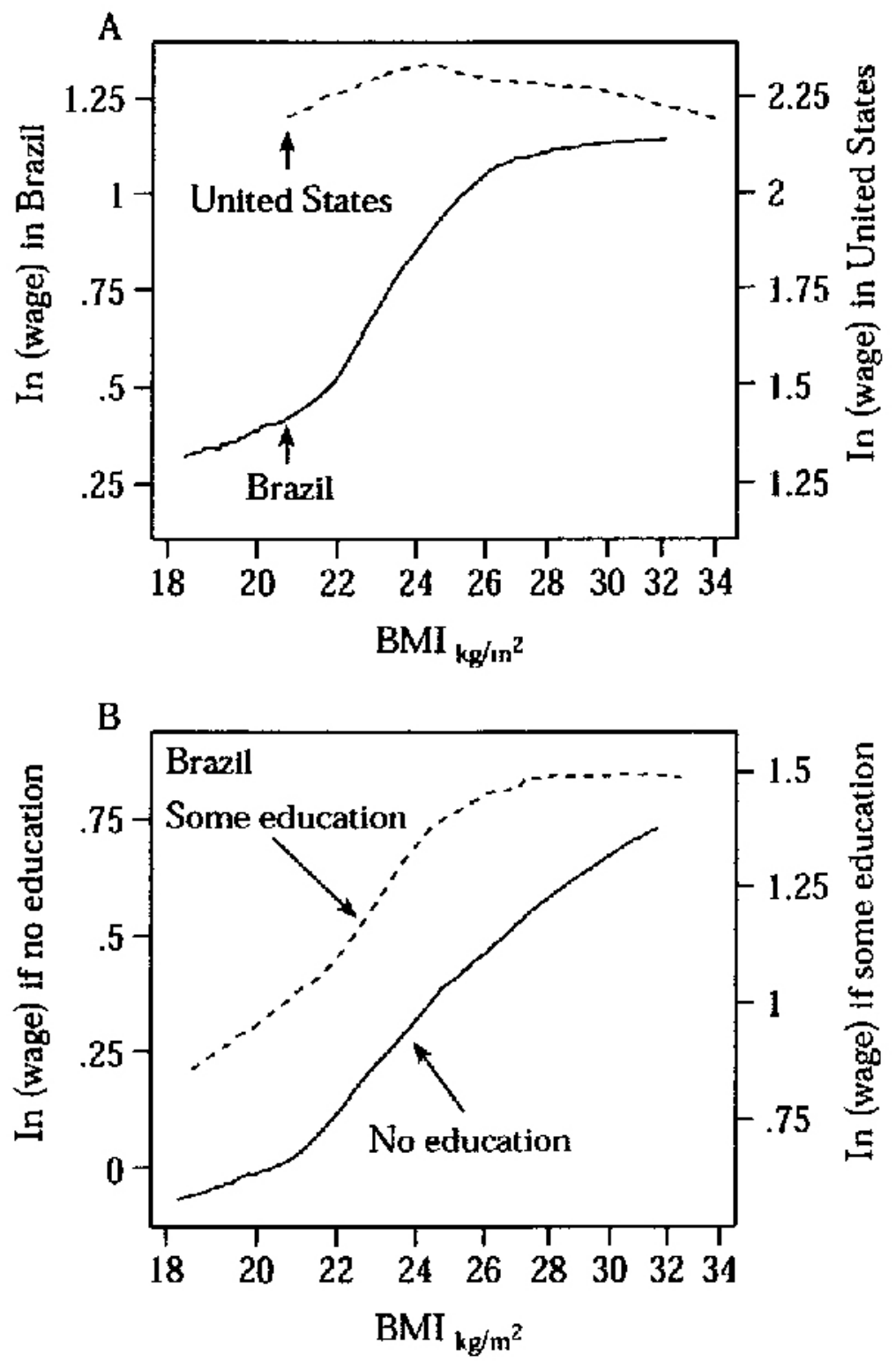

Source: Strauss and Thomas (1998)

Figure 5: Health and Labor Productivity 


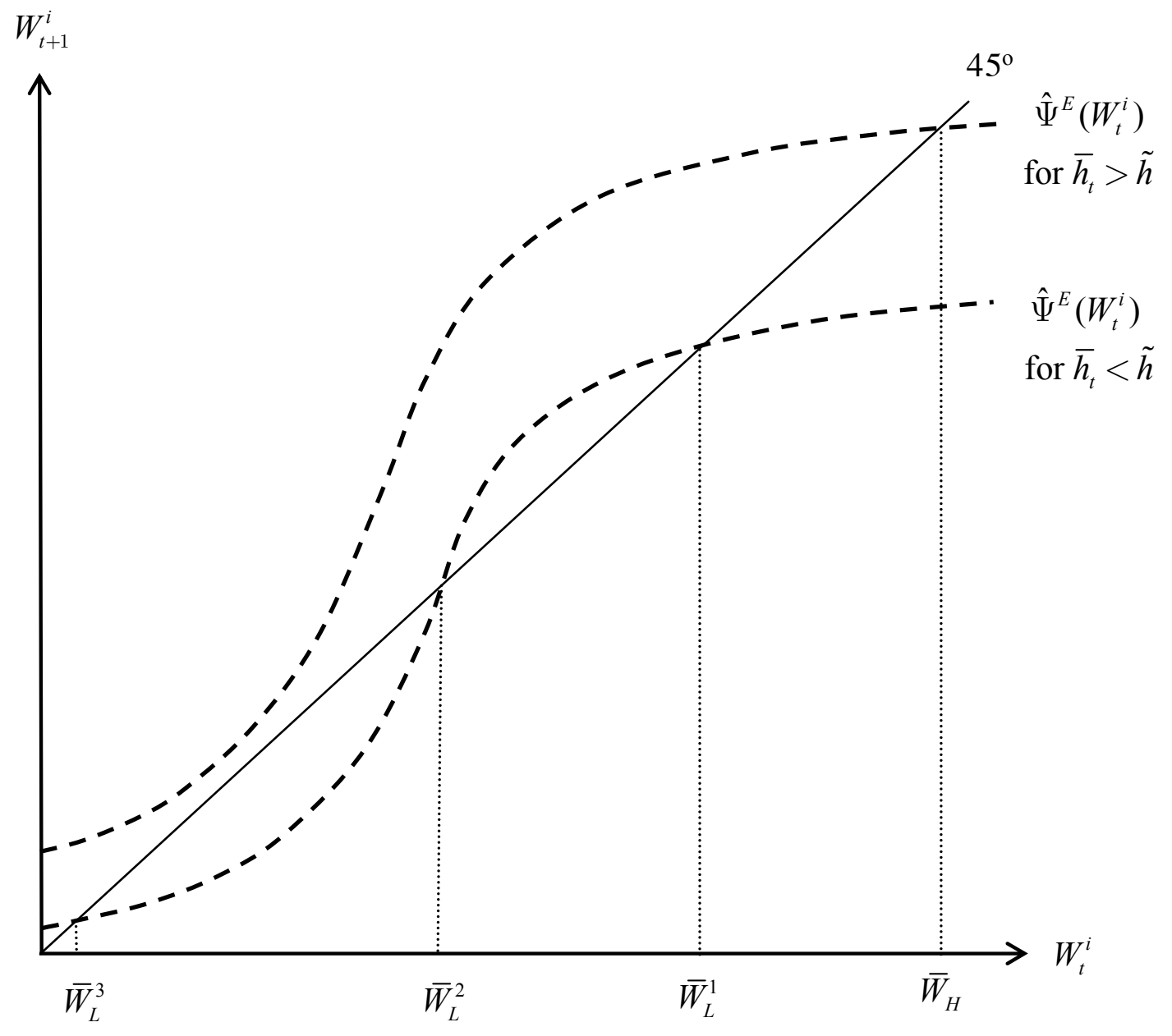

Figure 6: Wealth Dynamics with Health Externalities 